\title{
Variabilidad de recursos, habitat y movimientos estacionales en aves neotropicales: implicaciones para la evolución de la migración a larga distancia
}

\author{
D. J. LEVEY and F. GARY STILES
}

Authors' note At the time this paper was presented at the Quito symposium, it was already accepted for publication in American Naturalist, and consequently it has not been possible to reproduce it in full here. To retain it in some form for this volume, at the request of the editors F.G.S. drafted the version below, which represents an extended Spanish summary; however, for the full text, data and complete analysis it is necessary to consult the original article (Levey and Stiles 1992).

Nota de los autores A la fecha de ser presentado en el simposio en Quito, este trabajo había sido aceptado para la publicación en la revista American Naturalist y, por esto, no era posible presentar aquí el artículo completo. Para poder incluirlo en este volumen, a petición de los editores, F.G.S. preparó la presente versión, que equivale a un extenso resumen en español; los interesados en consultar el texto, los datos y los análisis completos pueden referirse al artículo original (Levey and Stiles 1992).

Varios estudios en los últimos 20 años han demostrado que la migración ocurre en varias escalas del espacio y el tiempo en las aves neotropicales. La supuesta dicotomía entre las aves sedentarias y las migratorias a larga distancia no existe: se encuentran muchos tipos intermedios de movimientos estacionales. Menos reconocidos son los paralelos ecológicos y evolutivos entre especies que muestran diferentes grados de migración. En este trabajo exploramos en detalle estos paralelos para demostrar como una mejor comprensión de los movimientos de corta distancia entre las aves terrestres "residentes" neotropicales, puede iluminar nuestro entendimiento de la migración a larga distancia entre las regiones neártica y neotropical.

Postulamos que las aves tropicales que dependen de recursos variables en el tiempo y el espacio necesitan hacer movimientos estacionales en varias escalas, y que tales movimientos podrían haber facilitado la evolución a larga distancia en ciertas de estas aves. Desarrollamos la hipótesis de que muchas aves migratorias del neártico se derivaron de grupos neotropicales que dependen de recursos estacionales y emparchonados y/o que viven en hábitats abiertos (es decir, donde incide directamente la luz solar: el dosel y los brodes del bosque, 
además de los sabanas y el crecimiento secundario fuera del bosque) y estacionales. Un corolario es que una mejor comprensión del por qué de las migraciones de las aves neotropicales nos ayudaría a entender por qué emigran las aves neárticas, y algo de su ecología invernal. Primero examinamos los factores ecológicos correlacionados con el comportamiento migratorio de las aves neotropicales. Buscamos paralelos ecológicos y taxonómicos entre las aves migratorias neotropicales y neárticas, y finalmente evaluamos nuestra hipótesis a través de dos predicciones sobre cuáles grupos de aves passeriformes estaban más o menos predispuestos a desarrollar la migración a larga distancia.

La reproducción de las plantas debe ser más variable en el espacio y el tiempo que la producción del follaje, porque esta última (concretamente, la fotosíntesis) es necesaria para que la planta acumule las reservas que permiten la reproducción. Dadas la variaciones del medio, las reservas que puede acumular una planta para la reproducción pueden variar mucho entre las épocas del año, y de un año a otro. Por esto los recursos para las aves relacionados con el follaje (incluyendo la gran mayoría de los insectos) suelen ser más constantes y predecibles en el tiempo y el espacio, que los relacionados directamente con la reproducción (como el nềctar y los frutos). Esta variabilidad debe ser aún mayor en los hábitats abiertos, más expuestos a las variaciones climáticas, que en el interior del bosque tropical. Como las copas de los árboles del dosel son más grandes que las de las plantas del sotobosque, los recursos del dosel presentarían más heterogeneidad espacial, a una escala mayor, que los del sotobosque. Por estas razones, postulamos que las aves frugívoras y nectarívoras, y las del dosel, los bordes y afuera del bosque, deberían incurrir en más movimientos estacionales que las aves insectívoras del sotobosque.

Evaluamos esta hipótesis con datos de la avifauna forestal de la vertiente del Atlántico de Costa Rica. Elaboramos clasificaciones sencillas de dieta, hábitat, y movimientos estacionales para estas aves. Reconocemos cinco grupos basados en la dieta: insectos pequeños, insectos grandes y vertebrados pequeños, vertebrados más grandes, néctar, y frutos y semillas. Para ciertas especies, evaluamos la importancia de los frutos en la dieta como ninguna, poca, o mucha según los registros publicados de frugivoría (probablemente un indicador conservador en este sentido). La clasificación de hábitats incluye cuatro categorías: aéreo; dosel y borde del bosque; interior del bosque; y afuera del bosque. Los grados o tipos de movimientos estacionales fueron clasificados como: sedentario (no hay movimientos poblacionales); movimientos locales; migraciones altitudinales; y migraciones intratropicales. Si bien tales clasificaciones simples no pueden tomar en cuenta los recursos específicos que requiere cada especie, tienen la ventaja de que permiten comparaciones más amplias.

La presencia de la migración altitudinal resulta estar fuertemente relacionada con la dieta: es mucho más frecuente entre las especies frugívoras y nectarívoras, que entre las que comen insectos o vertebrados. La gran mayoría de los migradores altitudinales son especies del dosel o del borde del bosque: en cambio, muy pocas especies del sotobosque hacen tales migraciones. Estos patrones son generales, y no el resultado de la influencia de unos grupos taxonómicos. En la gran familia Tyrannidae (los mosqueros o atrapamoscas), por ejemplo, el grado del comportamiento migratorio está estrechamente relacionado con el grado de frugivoría. Entre las especies de Turdidae (mirlos y zorzales) existe 
una asociación casi perfecta entre hábitat, dieta, y comportamiento migratorio: las especies del sotobosque son insectívoras y sedentarias, las del dosel y los bordes son más frugívoras y migratorias. En la familia Cotingidae, el grado de comportamiento migratorio también está correlacionado con el grado de frugivoría. Entre los Caprimulgiformes, la única especie frugívora es la más migratoria; entre las insectívoras, la migración es más frecuente entre las especies de hábitats abiertos que entre las del bosque. En los colibríes (Trochilidae), todos toman néctar y la mayoría realiza movimientos estacionales. Las migraciones altitudinales caracterizan especialmente a las especies del dosel; los movimientos locales a las especies del borde o afuera del bosque; las especies del sotobosque son las más sedentarias.

Se ha encontrado que entre los Tyrannidae, las especies migratorias tienen dietas más amplias y variadas que las especies sedentarias. Esto ha llevado a ciertos autores a postular que el oportunismo o flexibilidad dietaria puede haber facilitado la evolución de la migración en ciertos grupos. Nosotros creemos que tal oportunismo es más probablemente una consecuencia y no una causa del comportamiento migratorio. Para un ave muy oportunista, sería más fácil cambiar su dieta para acomodarse a los cambios de los recursos a nivel local, sin la necesidad de la migración. Una vez evolucionado el comportamiento migratorio en respuesta a otros factores, un grado de flexibilidad $\mathrm{u}$ oportunismo en la dieta bien puede ser favorecido para permitir al ave acomodarse a cambios impredecibles en la disponibilidad de recursos a lo largo de su trayectoria migratoria.

La conclusión de este análisis es que existe una relación fuerte entre la dieta (en particular, el consumo de frutos o néctar), el hábitat (especialmente la ocupación de hábitats "abiertos", en el sentido amplio), y el grado de comportamiento migratorio en las aves "residentes" de Costa Rica. Ahora proponemos que la migración a larga distancia es simplemente una extensión de esta relación, y que los grupos más dispuestos a hacer migraciones dentro de los trópicos, eran los más predispuestos a emprender migraciones hacia afuera de los trópicos. Para evaluar esta hipótesis, examinamos las relaciones taxonómicas y ecológicas entre migratorios de larga distancia (especialmente, su ecología en el área de invernada), y las especies tropicales migratorias.

De las 162 especies de aves migratorias del orden Passeriformes registradas en Costa Rica, casi la mitad incluye cantidades significativas de frutos en sus dietas invernales. Las especies más frugívoras también presentan un mayor grado de movilidad dentro de sus áreas de invernada; las especies más insectívoras tienden a ser territoriales y sedentarias durante su permanencia en los trópicos. En la familia Tyrannidae, las especies más frugívoras también hacen migraciones más largas que las especies más estrictamente insectívoras. En ciertos grupos (Catharus, Piranga, Tyrannus), especies invernantes muestran migraciones locales, altitudinales, o intratropicales, exactamente análogos a las de sus congéneres "residentes". En Costa Rica (pero tal vez no en México), relativamente poca especies migratorias habitan el sotobosque del bosque húmedo tropical.

Si la dependencia de recursos relacionados con la reproducción de las plantas, y/o la ocupación de hábitats abiertos y estacionales fueran precursores evolutivos para el desarrollo de la migración a larga distancia, esperaríamos 
que las familias de aves "residentes" con estas características, incluyeran más especies de migradores latitudinales que las familias más insectívoras y del sotobosque. Este patrón es claro en las àves de Costa Rica: familias que son completamente insectívoras y habitan el sotobosque no tienen aves migratorias, y solamente una familia (Troglodytidae, los cucaracheros) completamente insectivora incluye algunas especies migratorias. Sin embargo, ningún miembro migratorio de esta familia se aleja hasta Costa Rica desde su zona de cría, y las especies migratorias son de hábitats abiertos. En cambio, seis de ocho familias frugívoras han desarrollado la migración a larga distancia. Sin embargo, hay algunas excepciones. Las reinitas (Parulidae) constituyen el grupo más grande de especies migratorias que llega a Costa Rica, pero relativamente pocas son frugívoras y la mayoría no tiene congéneres tropicales. La explicación de esta falta de concordancia puede ser histórica: los géneros migratorios de esta familia evidentemente evolucionaron en la parte tropical de Norteamérica, y no en el neotrópico propiamente dicho. Esta área (México, norte de Centroamérica) se caracteriza por tener un clima, y probablemente recursos, más marcadamente estacionales y vegetación más abierta, que las zonas más estrictamente neotropicales, especialmente durante el Pleistoceno. Quizás en este grupo, la asociación con hábitats más estacionales fue el factor determinante, y no la dieta como tal. Es notorio que las especies neotropicales de esta familia (v. gr. Basileuterus) son casi todas insectívoras, sedentarias, y del sotobosque. Entre los Tyrannidae, el género Contopus es excepcional: las especies migratorias son exclusivamente insectívoras. Sin embargo, en este género todas las especies son de hábitats abiertos, y las especies migratorias también tienen dietas más amplias que las sedentarias.

Los paralelos ecológicos y taxonómicos entre las aves tropicales que son migratorias altitudinales, locales, o intratropicales y los migratorios neárticos en su área de invernar proporcionan evidencia adicional de que estos grupos no son entidades distintas: son practicamente indistinguibles en su taxonomía, dieta y uso del hábitat. El hecho de que muchas aves migratorias del norte sean más frugívoras en sus áreas de invernar que en sus áreas de anidación, puede interpretarse como a una reversión a su dieta ancestral más que al consumo de un tipo de alimento nuevo, en términos evolutivos. Ya que los frutos son pobres en proteínas, las ventajas para un ave frugívora de emigrar hasta la zona templada para anidar son evidentes dada la abundancia de insectos en estas latitudes en la primavera y el verano. Hay evidencia de que muchas especies frugívoras tropicales consumen más insectos durante sus épocas de cría, y que la disponibilidad de insectos podría haber influido en la programación de la cría dentro de sus ciclos anuales. Así, limitaciones de proteína, para aves frugívoras, además de la inestabilidad y variabilidad de los frutos como recurso, pueden haber predispuesto a algunas de estas aves a emprender migraciones más largas.

Si bien la mayoría de los autores actuales están de acuerdo en que gran parte de las aves migratorias del neártico tienen sus orígenes en el neotrópico, los mecanismos para la evolución de la migración todavía no están bien entendidos. Lo que falta a los modelos propuestos es un análisis de las características ecológicas que podrían haber facilitado la evolución de la 
migración en las aves tropicales. Este es el análisis que hemos intentado presentar aquí. En particular, sugerimos que el punto de partida de estos modelos, el "ave tropical sedentaria", está equivocado: deber ser sustituido por el del "ave tropical migratoria".

\section{Referencia}

Levey, D. J. and Stiles, F. G. (1992) Resource variability and movement patterns of Neotropical landbirds: evolutionary precursors for the evolution of long-distance migration. Amer. Nat. 122: 447-476.

D. J. LEVEY

Department of Zoology, Bartram Hall, University of Florida, Gainsville, FL 32611, U.S.A.

F. GARY STILES

Instituto de Ciencias Naturales, Universidad Nacional de Colombia, A.A. 7495, Bogotá, D.E., Colombia. 